\title{
OUTCOME OF LATE ANTERIOR SURGERY AND ARTHRODESIS OF LOWER CERVICAL SPINAL CORD INJURY
}

\author{
CHOWDHURY SMNK ${ }^{1}$, AHMED SU ${ }^{2}$, ARA SA $^{3}$, CHOWDHURY SMMA $^{4}$, HOSSAIN SS $^{5}$, \\ BARUA KK ${ }^{6}$, HOSSAIN MA ${ }^{7}$
}

\begin{abstract}
:
Objective: To evaluate the efficacy and outcome of late anterior surgery and arthrodesis of lower cervical spinal cord injury.

Study design: Prospective Analysis. Setting: Department of Neurosurgery, Bangabandhu Sheikh Mujib Medical University (BSMMU) Dhaka; Bangladesh.

Subjects and Methods: 32 consecutive patients with sub axial cervical spinal cord injury managed surgically from January 2000 to July 2005 by late anterior surgery and autologous bone graft stabilization considered as study unit. The indications of surgery were persistent cervical spinal cord compression and / or instability of cervical spine. Most cases were admitted late and operations were carried out as late 1 week to 27 weeks after injury. All the patients were investigated by radiograph and MRI of cervical spine accordingly. Post operative patient were followed up for twice, just before discharge from hospital and there-after minimum 3 months to 3 years. Quantification of deficit and neurological outcome were rated by American Spinal Injury Association (ASIA) classification system.

Results: Males were found predominant with 93.75\% over the female 6.25\%; with ratio is 15: 1 . Minimum age of the patient is 16 years and maximum age is 55 years. Most frequently (37.50\%) encountered group were between the age of 31 to 40 years. Mean age is 32.29 10.09 years. Falling due to slip while carrying heavy load on head and / or neck (37.50\%) was the most common cause of sub axial cervical spinal injury followed by road traffic accidents (31.25\%), which may not be reported elsewhere till to-date. $31.25 \%$ suffered a single vertebral level, $62.50 \%$ patients suffered two vertebral levels and $6.25 \%$ patients suffered three level vertebral levels. The commonest skeletal level was $C_{5 / 6}(46.87 \%)$ followed by $C_{5}(25.00 \%)$ but $C_{5}(46.87 \%)$ was commonest neurological level followed by $C_{4}$ (18.75\%). $81.25 \%$ of patients sustained a neurological injury. Of these, $75.00 \%$ had incomplete neurological deficit. After the operative procedure these incomplete neurological deficit patients have shown very attractive neurological recoveries. $6.25 \%$ of total population, who had complete neurological deficit, was graded as ASIA grade - A did not show any neurological recovery. In the current series none of the patients had worsening of neurological deficit due surgical intervention. Conclusion: This study offer significant potential for repairing some of the damage caused by cervical spinal cord injury. Further more, though controversy exists as to the ideal approach and timing (early versus late surgery) we have seen that benefits derived from late anterior surgery in our patients.
\end{abstract}

Key words: Spinal Cord Injury, ASIA impairment scale. Neurological outcome.

J Dhaka Med Coll. 2009; 18(1) : 47-53

\section{Introduction:}

Spinal injury has been pronounced by the ancient Egyptians as "an ailment not to be treated" mainly because of the neurological injury associated with it $^{1,2}$. Traumatic spinal cord injury (SCI) occurs primarily in young adults with more than half being between 16 to 30 years of age. Male accounts for about $80 \%$ of $\operatorname{cases}^{3,4} \cdot 30-50 \%$ of these patients have complete injuries with no motor or sensory function below the level of injury and $60 \%$ of these spinal injures involve the cervical spinal

1. Assistant Professor, Department of Neurosurgery, Dhaka Medical College, Dhaka.

2. Associate Professor, Department of Surgery, Bangabandhu Sheikh Mujib Medical University, Dhaka.

3. Resident, Department of Pathology, Chittagong Medical College, Chittagong.

4. Resident, Department of Cardiology, Chittagong Medical College Hospital, Chittagong.

5. Professor \& Head, Department of Neurosurgery, Dhaka Medical College, Dhaka.

6. Professor, Department of Neurosurgery, Bangabandhu Sheikh Mujib Medical University, Dhaka.

7. Professor \& Chairman, Department of Neurosurgery, Bangabandhu Sheikh Mujib Medical University, Shahbag, Dhaka.

Correspondence: Dr. Sharif Md Noman Khaled Chowdhury 
region. The most common affected site was found between the $\mathrm{C}_{4}$ and $\mathrm{C}_{6}$ vertebra, $20 \%$ of patients with major a spinal injury have a second spinal injury at another level, which may be noncontiguous ${ }^{5}$. Severity of the spinal cord injury and the final out come depends upon: The mechanism of the injury, the severity of the force applied and duration of the spinal cord compression ${ }^{6}$. Many controversies have yet to be resolved regarding the management of cervical spinal injuries. The goals of treatment are to make re-establishing or maintaining neurological function and establishing spinal stability. Older literature was pessimistic about the role of surgery ${ }^{7,8}$. Others were unable to document a difference in outcome ${ }^{9}$. Neurological improvement was document in another series with anterior decompression ${ }^{10,11}$. Recent advances in the safety and efficacy of surgical decompressive techniques to treat the spinal cord injuries offer significant potential for reparing some of the damage caused by spine injuries ${ }^{12}$. For example, Tator et al ${ }^{13,14}$ have observed $56 \%$ in a prospective series of 208 patients with acute SCI underwent at least one spinal operation, and retrospective series of 1385 patients, $75 \%$ of patients underwent surgical treatment. However, controversy exists as to the ideal timing (early versus late) and the benefits derived from undergoing acute decompressive surgery after acute $\mathrm{SCI}^{15,16}$. Definitive and unequivocal evidence to support the practice of early or late surgery is still lacking in clinical studies ${ }^{17}$. A review of the current evidence available in the literature suggests that there is no standard of care regarding the role and timing of surgical decompression. There are insufficient data to support overall treatment standards or guidelines for this topic ${ }^{18-20}$.

Propenents for early surgical decompressive procedures argue that early intervention may halt rapid progression of pathological changes known to occur in the injured spinal cord and thus also prevent neurological deterioration in the patients ${ }^{14,18,21-23}$. On the other hand, authors of several reports in the literature warn against performing early surgery in these critically injured and medically unstable patients $^{24,25}$. Marshall et al. found that more patients worsened neurologically after early surgery ( $<5$ days) ${ }^{24}$. The prognosis of central cord syndrome in cervical trauma related patient is known to be favorable with delayed management as some time-related spontaneous neurological recovery is expected. Furthermore, in the acute stage, the possibility for secondary injury from the manipulation of edematous spinal cord and drug-induced hypotension during surgery should be strongly considered $^{26}$. The authors of several other studies have reported improved neurological outcome in patients who underwent late decompressive surgery days, weeks or months post injury ${ }^{27-30}$. In patients of acute cervical spinal cord trauma requiring surgery, there are different opinions about the appropriate surgical technique, anterior versus posterior approach. Each has its merits and limitations. The advantages of anterior decompression include the ability to achieve a more through and complete decompression of the cord. The disadvantage of posterior decompression include progressive deformity and instability of the spine and possibly less recovery of neurological function due to less complete and through decompression of the spinal cord ${ }^{26}$.

Bohlman et al. and Zhang et al. had found that anterior decompression and arthrodesis, even when performed late after the injury, could improve neurological function in both the upper and lower extremities in many patients who have incomplete quadriplegia due to fracture or dislocation of the cervical spine ${ }^{27,31}$. The fact that nowadays so many different conservative and operative procedures are used for the treatment of cervical spine injuries reflects the lack of a clearly superior technique. We recognize that the treatment of cervical spine fractures and dislocations is not yet established and therefore feel that any well-considered procedure deserves consideration $^{32}$. Awareness of these led us to consider our approach to the management of patients with vertebral injury and cervical spinal cord compression; we adopted for these patients late anterior surgery with autologus bone graft stabilization as a single stage procedure, intending that this should both 
relieve pressure on the spinal cord, stabilize the spine and pave the way for early mobilization.

\section{Subjects and Methods:}

A prospective interventional study carried out in the Department of Neurosurgery, Bangabandhu Sheikh Mujib Medical University (BSMMU), Dhaka, Bangladesh from January 2000 to July 2004. Sample size was 32. All patients with sub axial cervical spinal cord injury managed surgically by late anterior surgery and autologus bone graft stabilization were considered as a study unit. The indications of surgery were persistent cervical spinal cord compression and / or instability of cervical spine. Most cases were admitted late and operations were carried out as late 1 (one) week to 27 (twenty-seven) weeks after injury. All the patients were investigated by radiograph and MRI of cervical spine accordingly. Quantification of deficit and neurological outcome were rated by the international standards for neurological and functional classification of spinal cord injury by American Spinal Injury Association (ASIA), endorsed by International Medical Society of Paraplegia (IMSOP). Evidences were Questionnaires, Examination tools and checklist, Radiological images, Operative notes, During the period of preceding surgery the patients were managed conservatively with Cervical Collar, GardnerWell Tong traction according to need by the clinical condition of the patient. Post operative patient were followed up for twice, just before discharge from hospital and there-after minimum 3 (three) months to 3 (three) years .Studied variables were- causes and characteristics of cervical spinal cord injury in our country, neurological recovery, stabilization, prevention of complications and enhancements of rehabilitation. Neurological outcome variable was ASIA impairment scale. Outcome of surgery was analyzed using student's paired " $\mathrm{t}$ " test, and conclusions were drawn based upon the $\mathrm{p}$ value at $0.05 \%$ level of significance.

\section{Observation and results:}

Among the total 32 (thirty-two) patients with sub axial cervical spinal injury, 30 (twenty-four) patients were male $(93.75 \%)$ and 2 (two) patients were female $(6.25 \%)$. Male and female ratio is 15: $1.81 .25 \%$ of these patients were under 40 years of age and remaining $18.75 \%$ patients were above 40 years of age. But most, i.e. $37.50 \%$ patients were between the ages of 31 to 40 years. Mean age was $32.29 \pm 10.09$ years. $62.50 \%$ accidents occurred in rural area and $37.50 \%$ accidents occurred in urban area. $31.25 \%$ suffered a single vertebral level, $62.50 \%$ patients suffered two vertebral levels and $6.25 \%$ patients suffered three level vertebral levels. In our series of sub-axial cervical spinal cord injury, the commonest skeletal level was $\mathrm{C}_{5 / 6}$ $(46.87 \%)$ followed by $\mathrm{C}_{5}(25.00 \%)$ but $\mathrm{C}_{5}(46.87 \%)$ was commonest neurological level followed by $\mathrm{C}_{4}(18.75 \%)$. In the present prospective study, $81.25 \%$ of patients who had sustained cervical vertebral column trauma sustained a neurological injury as result of that trauma. Of these neurological injuries, $75.00 \%$ had incomplete neurological deficit. As per increasing degree of neurological impairment, they were graded according to ASIA Impairment scale, as grade - D, grade - C, grade - B. $6.25 \%$ had complete neurological deficit, and according to ASIA Impairment scale, they were graded as grade - A. $18.75 \%$ were neurologically intact, and according to ASIA Impairment scale, they were graded as grade - E. In the present prospective study of sub axial cervical spinal injury, $12.50 \%$ of all incomplete, ASIA grade $B$ patients had showed recovery by ASIA grade - C, and $4.17 \%$ of all incomplete, ASIA grade $B$ patients had showed recovery by ASIA grade - D. But $8.34 \%$ of all incomplete, ASIA grade $B$ patients did not show any neurological recovery. $45.84 \%$ of all incomplete, ASIA grade - $\mathrm{C}$ patients had showed recovery by ASIA grade - D, But $12.50 \%$ of all incomplete, ASIA grade - C patients did not show any neurological recovery. $16.67 \%$ of all incomplete, ASIA grade - D patients enjoy complete neurological recovery (ASIA grade - E). $6.25 \%$ of total population who had complete neurological deficit, ASIA grade - A did not show any neurological recovery. $18.75 \%$ of total population who were neurologically intact, ASIA grade - E and operations have done to ensure cervical stability, and their neurological status 
were remain as before. Outcome of surgery was analyzed using paired student's " $t$ " test and conclusions drawn based upon the $\mathrm{p}$ value at $0.05 \%$ level of significance. It had been found that outcome of late anterior surgery and arthrodesis of lower cervical spinal cord injury was significant $(\mathrm{P}<0.05)$ statistically.

Table-I

Age distribution of the population

\begin{tabular}{lcc}
\hline Age in years & Number & Percentage \\
\hline $0-20$ & 6 & 18.75 \\
$21-30$ & 8 & 25.00 \\
$31-40$ & 12 & 37.50 \\
$41-50$ & 4 & 12.50 \\
$51-60$ & 2 & 6.25 \\
\hline Total & 32 & 100 \\
\hline
\end{tabular}

Table-II

Causes of cervical spinal injury

\begin{tabular}{lcc}
\hline $\begin{array}{l}\text { Causes of cervical } \\
\text { spinal injury }\end{array}$ & Number & Percentage \\
\hline $\begin{array}{l}\text { Fall due to slip while } \\
\text { carrying heavy load } \\
\text { on head }\end{array}$ & 12 & 37.50 \\
Road traffic accident & 10 & 31.25 \\
Fall of heavy load on head & 4 & 12.50 \\
Fall from height & 3 & 9.37 \\
Assault & 2 & 6.25 \\
Diving in shallow water & 1 & 3.13 \\
\hline Total & 32 & 100 \\
\hline
\end{tabular}

Table-III

Vertebral levels

\begin{tabular}{lcc}
\hline Vertebral level & Number & Percentage \\
\hline $\mathrm{C}_{4-5}$ & 3 & 9.37 \\
$\mathrm{C}_{5}$ & 8 & 25.00 \\
$\mathrm{C}_{5-6}$ & 15 & 46.87 \\
$\mathrm{C}_{6}$ & 2 & 6.25 \\
$\mathrm{C}_{6-7}$ & 2 & 6.25 \\
\hline Total & 32 & 100 \\
\hline
\end{tabular}

Table-IV Neurological levels

\begin{tabular}{lcc}
\hline Neurological levels & Number & Percentage \\
\hline $\mathrm{C}_{4}$ & 6 & 18.75 \\
$\mathrm{C}_{5}$ & 15 & 46.87 \\
$\mathrm{C}_{6}$ & 3 & 9,37 \\
$\mathrm{C}_{7}$ & 2 & 6.25 \\
\hline Total & 26 & 81.25 \\
\hline
\end{tabular}

Table-V

ASIA impairment scale (before operation)

\begin{tabular}{lcc}
\hline ASIA Grade & Number & Percentage \\
\hline E & 6 & 18.75 \\
D & 4 & 12.50 \\
C & 14 & 43.75 \\
B & 6 & 18.75 \\
A & 2 & 6.25 \\
\hline Total & 32 & 100 \\
\hline
\end{tabular}

Table-VI

ASIA impairment scale (after operation)

\begin{tabular}{lcc}
\hline ASIA Grade & Number & Percentage \\
\hline $\mathrm{E}$ & $6+4=10$ & $31.25 \%$ \\
$\mathrm{D}$ & 12 & $37.50 \%$ \\
$\mathrm{C}$ & 6 & $18.75 \%$ \\
$\mathrm{~B}$ & 2 & $6.25 \%$ \\
$\mathrm{~A}$ & 2 & $6.25 \%$ \\
\hline Total & 32 & $100.00 \%$ \\
\hline
\end{tabular}

\section{Discussion:}

In the current prospective series, age ranged from 16 to 55 years with mean age of $32.29 \pm 10.09$ years which is similar to recent published series ${ }^{15,33-34}$. The males were found predominant with $93.75 \%$ over the female $6.25 \%$; ratio is $15: 1$. Men accounts for about $80 \%$ of cases in western series ${ }^{34,35}$. Gupta et al. ${ }^{4}$ observed a male and female ratio is $17: 1$ in Indian people. Our male and female ratio is 15:1 is definitely higher than developed country. But this is not surprising in a country like Bangladesh where the majorities of women remain in home as housewives and are not subject to more violent form of accident to which the men are exposed. This supports the tenets of Kuhn who concluded that the sex ratio 
reflects the socio-economic and cultural status of a society. Falling due to slip while carrying heavy load on head and / or neck $(37.50 \%)$ was the most common cause of sub axial cervical spinal injury followed by road traffic accidents $(31.25 \%)$ in this series, which may not be reported till to-date elsewhere. This pattern of injury in our country is contrast to more developed countries, where the road traffic accidents were the main cause of cervical spinal injury ${ }^{4,35}$ followed by fall ${ }^{15,33,36}$. In this series, the commonest skeletal levels were $\mathrm{C}_{5}$ / ${ }_{6}(46.87 \%)$, followed by $\mathrm{C}_{5}(25.00 \%)$. But the commonest neurological levels were $\mathrm{C}_{5}$ (46.87\%), followed by $\mathrm{C}_{4}(18.75 \%)$. Bohlman ${ }^{37}$ described 300 acute cervical spinal fractures, $74 \%$ of which occurred between $\mathrm{C}_{4}$ and $\mathrm{T}_{1}$ levels. Sonntag et al. ${ }^{38}$ found that $72 \%$ of 1280 acute cervical spinal fracture subluxation injuries involved cervical segments $\mathrm{C}_{4}-\mathrm{T}_{1}$. Approximately $15 \%$ of patients who sustained vertebral column trauma sustain a neurological injury as a result of that trauma ${ }^{39,40}$. It is found that $40 \%$ to $60 \%$ of all cervical spine injuries result in neurological compromise, with a range between $2 \%$ to $100 \%$ depending on the type and level of cervical spine injury ${ }^{37,39,41-}$ 46. There are many methods available for surgical decompression and stabilizations for unstable' sub axial cervical spine with obvious merits to both anterior and posterior approach. So, the question is what kind of surgery should we like to perform? When any decompression of neural element is planned, the pathology should be attacked directly ${ }^{47}$. However, the severity of the primary spinal cord injury continues to be the prime determinant of neurological outcome in most cases. In presence of large anteriorly located space occupying lesion, the recommendation of Tator et al. was to perform an anterior decompression ${ }^{14}$.

The benefits of emergency decompression in cervical trauma are controversial. Our opinion is that decompressive surgery in a patient, who is neurologically intact, should be carried out under optimal circumstances to preserve cord function. Our protocol, the treatment of choice is conservative management with skeletal traction and then evaluation of the patient's neurological status is done. At that time one would be faced two considerations: Firstly is surgical decompression at the compressed level required and could it possibly maximize the neurological improvement? And secondly, how could further spinal cord injury be prevented? Even though many may not agree with the benefits of delayed surgical decompression, we have seen further progressive improvement of neurological deficits in many of our patients and these are the major novelty of our current series.

A more controversial situation is a patient with a partial spinal cord injury and ongoing compression. Based upon path physiology of secondary injury, the presence of cord compression may impede regional blood flow at the site of injury and promote secondary injury. Therefore, decompression may optimize the regional milieu, within which the spinal cord can recover ${ }^{15}$ and potentially counteract some of the factors involved in accelerating secondary spinal cord injury. Unfortunately, no prospective data exist ${ }^{13}$.

With these considerations we believe that decompression surgery is to be truly necessary. There are two ways of surgical decompression, anterior and posterior; and in our current series surgery via ventral approach is done since space occupation in these patients was caused mainly by the ventral structures .Others also observed in cervical spinal injured patients with persistent neurological compression who are candidates for surgical decompression, the majority will have the neurocompressive mass lesion located ventral to the neural elements ${ }^{36,41}$. Under these circumstances, "the appropriate procedure is an anterior approach". After achieving an adequate neural decompression, an appropriate cervical fusion is carried out using a tri-cortical iliac auto graft with or without a plate to reconstruct the spine. In the current series incomplete neurological deficit patients have shown very attractive neurological recoveries, none of the patients had worsening of neurological deficit due surgical intervention. We do not have any comparative study in our country in this regard and we convinced that our results are encouraging. 


\section{Conclusion:}

Results of this study offer significant potential for repairing some of the damages caused by cervical spinal cord injury. Recent advances in the safety and efficacy of surgical decompressive techniques in this arena are highly encouraging. The issue of the ideal timing (early versus late surgery) only is resolved by studying a large number of patients in a prospective randomized controlled study.

\section{References:}

1. Breasted JH. The Edwin Smith Papyrus: published in facsimile and hieroglyphic transliteration with translation and commentary in two volumes. Chicago: University of Chicago Press, 1930.

2. Feldman RP, Goodrich JT: The Edwin Smith surgical papyrus. Childs Nerv Sys. 1999; 15: 2814 .

3. Go BK, DeVivo MJ, Rechards JS. The epidemiology of spinal cord lesion. In: Stover SL, Delisa JA, Whteneck GG. eds. Spinal Cord Lesion. Gaitherburg: Aspein; 1995. p.21-5.

3. Greenberg SM: Handbook of Neurosurgery. $5^{\text {th }}$ ed. Florida: Greenberg Graphics Inc. p.2166.

4. Gupta A, Taly AB, Srivasta A, Vishal S, Murali T. Traumatic vs nontraumatic spinal cord lesions: comparison of neurological and functional outcome after in patient rehabilitation. Spinal Cord. 2000; 46: $482-7$.

5. Bharatwal M. Acute management of cervical spinal injury. In: Singh A K. ed. Indian Clinical Neurosurgery. Vol. 1. $1^{\text {st }}$ ed. New Delhi: CBS Publishers; p.249 -51.

6. Bebrook GM. Recent advances in the management of spinal injuries with paralysis. Aus NZ J Surg. 1977; 43: 330-8.

7. Guttman L. Spinal cord injuries: comprehensive management and research. Philadelphia: F A Davies; 1973; 19: 111-2.

9. Dall DM. Injuries of cervical spine: does anatomical reduction of the bony injuries in the prognosis for spinal recovery? S Arf Med J. 1972; 46:1083-90.

10. Horseey WJ, Tucker WS, Hudson AR. Experiences with early anterior operation in acute injuries of cervical spine. Paraplegia. 1978; 15: 319-26.

11. Bohlman $\mathrm{HH}$, Anderson PA. Anteroir decompression and arthrodesis of the cervical spine in term of motor improvement. Part I improvement in incomplete traumatic quadriparesis. J Bone Joint Surg. (Am). 1992; 74(5): 671-82.

12. Wilberger J. Diagnosis and management of spinal cord trauma. J Neurotrauma. 1991; 8 (Suppl 1): 21-30.

13. Tator $\mathrm{CH}$, Duncan EG, Edmonds VE, et al. Comparision of surgical and conservative management in 208 patients with acute spinal cord injury. Can J Neurol Sci. 1987; 14: 60-9.

14. Tator $\mathrm{CH}$, Fehlings $\mathrm{MG}$, Thorpe K, Taylor W. Current use and timing of spinal surgery for management of acute spinal cord injury in North America, result of retrospective multi center study. J Neurosurg. 1999; 91(1): 12-18.

15. Levi L, Wolf A, Rigamonti D, et al. Anterior decompression in acute cervical spinal trauma: does the timing of surgery affect the outcome? Neurosurgery. 1991; 29: 216-22.

16. Vaccaro AR, Daugherty RJ, Sheehan TP, et al. Neurologic out come of early versus late surgery for cervical spinal cord injury. Spine. 1997; 22: 2609-13.

17. La Rosa G, Conti A, Cardalis S, et al. Does early decompression improve neurological outcome of spinal cord injured patients? Appraisal of literature using a meta-analysis approach. Spinal Cord. 2004; 42(9): 503-12.

18. Fehlings MG, Sekhon-Lali HS, Tator C, et al. The role and timing of decompression in Acute Spinal Cord Injury: what do we know? what should we do? Spine. 2001; 26 (24S): S101-S110.

19. Pollard ME, Apple DF. Factors associated with improved outcomes in patients with incomplete tetraplegia. Spine. 2003; 5: 383-9.

20. Yamazaki Y, Tachibana S, Ohwada T, Yada K. The neurological outcome in patients with acute cervical spinal cord injury. [Article in Japanese] [Abstract]. No Shinkei Geka. 1992; 20(4): 319-23.

21. Bracken MB, Shepard MJ, Collin WF, et al: A randomized control led trial of methylprednisolone or nalaxone in the treatment of acute spinal cord injury: results of the second National Acute Spinal Cord Injury Study. N Engl J Med. 1990; 322: 140511 .

22. Mirza SK, Krengel WF, Chapman et al. Early versus delayed surgery for acute cervical spinal cord injury. Clin Ortho and Related Res. 1999; 359: 104-14.

23. Papadopoulos SM, Selden NR, Quint DJ, et al. immediate spinal cord decompression for cervical spinal cord injury: feasibility and outcome. J Trauma. 2002; 52(2): 323-32. 
24. Marshall LF, Knowlton S, Garfin SR, et al. Deterioration follwing spinal cord injury: a multicenter study. J Neurosurg. 1987; 66: 400-4.

25. Wolf A, Levi L, Mirvis S, et al. Operative management of bilateral facet dislocation. J Neurosurg. 1991; 75: 883-90.

26. Kim YS et al. Surgical management of incomplete cervical cord injury with stenosis secondary to OPLL, Spinal Cord. 2000; 38: 140-5.

27. Anderson PA, Bohlman HH. Anteroir decompression and arthrodesis of the cervical spine in term motor improvement. Part II improvement in complete traumatic quadriplegia. J Bone Joint Surg. (Am). 1992; 74: 683-92.

28. Demopolus HB, Flamm ES, Pietronigro DD, et al. The free radical pathology and microcirculation in the major central nervous system disorders. Acta Physol Scand Suuppl. 1980; 49: 117-9.

29. Larson SJ, Holst RA, Hemmy DC, et al. Lateral extracavitary approach to traumatic lessionsof the thoracic and lumber spine. J Neurosurg. 1976; 45: 628-37.

30. Miman DJ, Larson SJ, Benzel EC. Neurological improvement associated with late decompression of thoracolumber spinal cord. Neurosurgery. 1984; 14: 302-7.

31. Zhang $\mathrm{HQ}$, Li KH, Long WR. Anterior approach in the surgical treatment of cervical injury fracture and spinal cord injury. [Article in Chinese] [Abstract]. Hunan Yi Ke Da Xue Xue Bao. 2002; 27(2): 139-42.

32. Bucy P. Editorial. Surg Neurol. 1984; 21: 587.

33. DeVivo MJ. Trends in spinal cord injury demographics and treatment outcomes between 1973 and 1986. Arch Phys Med Rehabil. 1992; 73: 424-30.

34. Frankel HL, Coll JR, Charlifue SW, et al: Long term survival in spinal cord injury: a fifty year investigation. Spinal Cord. 1998, 36: 266-74.

35. McKinly WO, Huang M, Tewksbury MA. Neoplastic vs traumatic spinal cord lesion: an international rehabilitation comparision. Am J Phys Med Rehabil. 2000; 79: 138-44.
36. Whitneck GG. Mortality, morbidity and psychological outcomes of persons with spinal cord injuried more than 20 years ago. Paraplegia. 1992, 30: 617-30.

37. Bohlman HH. Acute fracture and dislocations of the cervical spine: an analysis of three hundred hospitalized patient and review of the literature. J Bone Joint Surg. (Am). 1979; 61-A: 1119-42.

38. Sonntag VKH, Hadley MN. Management of non odontoid upper cervical spine injury. In: Cooper P. ed. Management of posttraumatic spinal instability. Neurosurgical topics. AANS publications; 1990. p.99-109.

39. Wesis J. Mid and lower cervical spine injuries. In: Wilkins R. ed. Neurosurgery: New York: McGraw-Hill; 1985. p.1708-15.

40. Sonntag VKH, Hadley MN. Management of upper cervical spine instability. In: Wilkins R. ed. Neurosurgery Update. New York: McGraw-Hill; 1991. p.222-3.

41. Bohlman HH, Boada E. Fracture and dislocation of the lower cervical spine. In: Cervical Spine Research Society. ed. The Cervical Spines. Philadelphia: JB Lippincott. 1983. p.232-67.

43. Harris P, Karmi MZ, McCloment E, Mathoko D, Paul KS. The prognosis of patients sustaining severe cervical spine injury $\left(\mathrm{C}_{2}-\mathrm{C}_{7}\right.$ inclusive $)$. Paraplegia. 1980, 18: 324-30.

44. Heidin JS, Weiss MH. Cervical spine injuries with and without neurological deficit. Int Contemp Neurosurg. 1980; 2: 1-6.

45. Mesard L, Carmody A, Mannarino E, Ruge D. Survival after spinal cord trauma: a life table analysis. Arch Neurol. 1978; 35: 78-83

46. Riggins RS, Kraus JF. The risk of neurologic damage with fracture of vertebrae. J Trauma.1977; 17: 126-33.

46. Hadley MN, Fitzpatrick B, Browner C, Sonntag VKH. Facet fracture -dislocation injuries of the cervical spine. Neurosurgery. 1992; 30: 661-6.

47. Schmidek HH, Sweet WH. eds. Operative Neurosurgical Techniques: Indications, Methods and Results. Vol. 2. $3^{\text {rd }}$ ed. Philadelphia: WB Saunders Company. 